\title{
Branching arguments
}

\section{Kevin Padian considers two books on tree diagrams and what they can represent.}

$\mathrm{W}$ hen we represent the relationships of organisms, our thoughts turn naturally to trees. We draw genealogical family trees, and often think of great apes as part of our extended family. (Some of them even live in trees.) Trees' progressively smaller branching lends itself as a visual metaphor for the diversification of life.

This is problematic: diversification has not always meant evolution as we think of it today. Nineteenth-century authors from geologist Charles Lyell to naturalist Richard Owen plotted the diversification of fossil organisms through layers of the geological column, but most did not regard it as a transmutation of species. Instead, it was seen as a record of life's history. The processes producing that pattern were not accepted until Charles Darwin published On the Origin of Species in 1859.

Darwin convinced people that all living beings had one or a few common ancestors, so treelike diagrams became, for the first time, literal genealogical representations of those relationships. However, Victorian authors who used them were not always depicting evolutionary relationships - they could just be showing affinities. All sorts of connecting diagrams can unite creatures that have four digits, are insectivores or live in New Zealand, without suggesting any genealogical connection.

Two books now get to grips with the tree as a pictorial device. Biologist David Archibald's Aristotle's Ladder, Darwin's Tree interweaves the history of treelike diagrams with their changing meanings as they came to represent different kinds of statement about relationships. Designer Manuel Lima's Book of Trees explores the many possibilities presented by these diagrams in expressing ideas and discoveries, with a strong emphasis on the effectiveness of representational strategies.

Archibald shows how Darwin wrestled

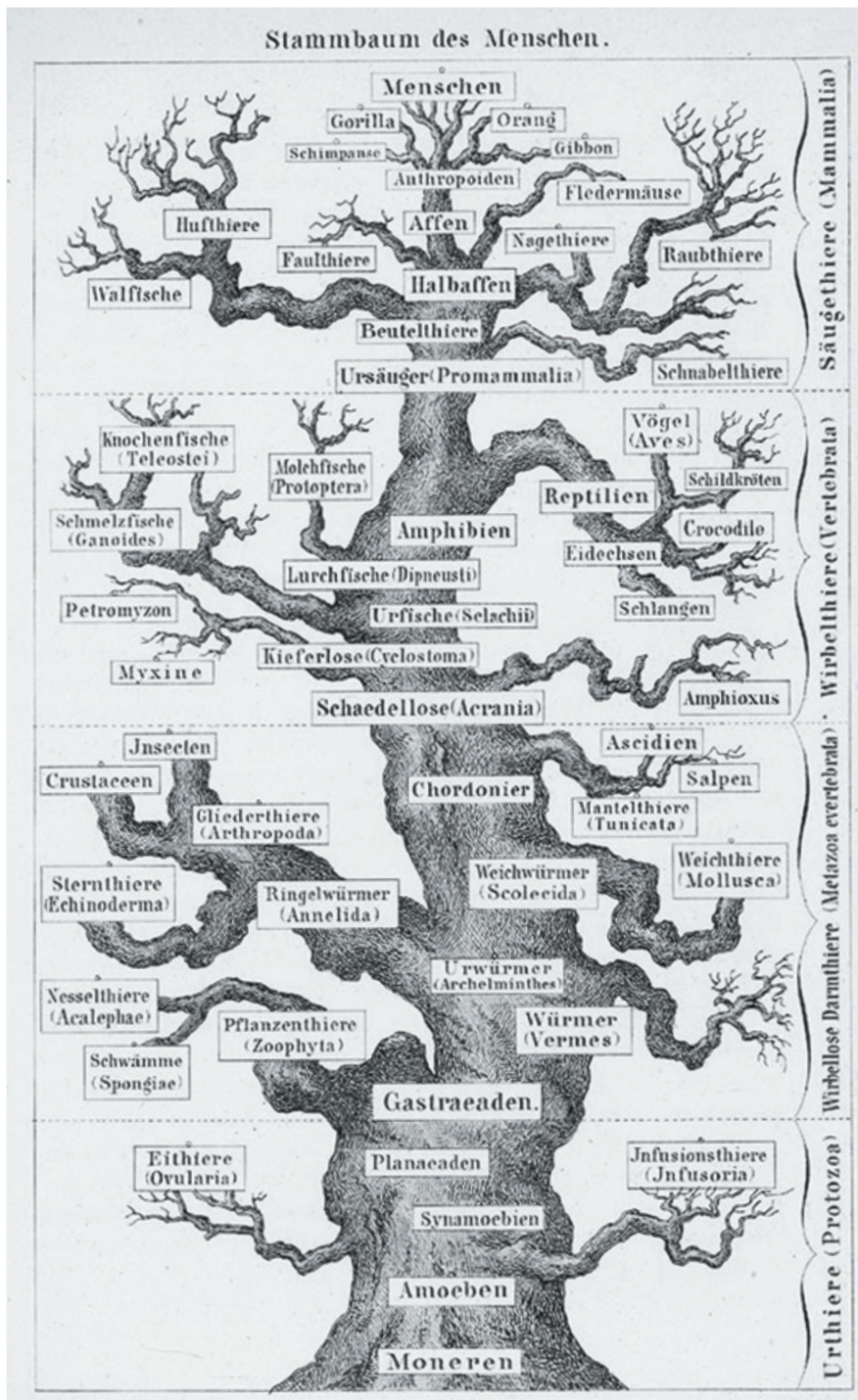

represent the vast and largely unknown fossil record.) The book tracks tree iconography back to ancient Rome, where it was used to portray family histories of prominent citizens, and traces the same leafy configurations through early Christian schemes of prophets and saints. How could such a useful device not have come to serve so many conceptual purposes?

Discussing the phenomenon now, Archibald shows that in the modern synthesis of evolution - the neo-Darwinian movement that dominated evolutionary theory from the 1930s - taxonomies were originally relatively free-wheeling. Taxonomists ranked organisms in arbitrary systems according to perceived differences or importances; thus, humans could be separated from (other) apes into a different sub-family, family or even order. Archibald also clarifies cladistics, the current preeminent system of systematics, in which genetic proximity is the only criterion for building trees of life (as Darwin thought). In cladistics, newly evolved characteristics (synapomorphies) are prized for their ability to reflect the common ancestry of all the creatures who possess them, compared with those who do not. The treelike cladogram is the ultimate arrangement of groups of creatures according to shared possession of characteristics -

with whether the metaphor of a tree, coral or endlessly dividing seaweed would best represent the genealogies of life. (Corals were attractive because they are alive only at their tips; their nether branches would thus

Aristotle's Ladder, Darwin's Tree: The Evolution of Visual Metaphors in Biological Order

J. DAVID ARCHIBALD

Columbia University Press: 2014.

The Book of Trees: Visualizing Branches of

Knowledge

MANUEL LIMA

Princeton Architectural Press: 2014. transparent in its data, and stringent in its method.

The devil, of course, is in the details of interpreting characteristics in different creatures and choosing the algorithms by which to group them, a process now eased by computer programs. Archibald shows how the rise of methods for extracting and analysing data on similarities in DNA has also revolutionized systematics. These chapters are among the best short treatments of the subject anywhere.

Even in the current hegemony, however, confusion persists. Just as classical treelike diagrams did not always imply relationships, 
phylogenetic trees and cladograms convey different ideas. Many students are taught that 'a tree is a cladogram with time attached'. But cladograms are merely diagrams of the distribution of characteristics. You can make cladograms of chocolate bars, hardware or cartoon characters, as long as you clarify how you are identifying the synapomorphies. A phylogenetic tree, by contrast, depicts evolutionary relationships. You can put putative ancestors in a tree's branches (most no longer do so, because we can seldom identify direct ancestors), but not in a cladogram. A cladogram has no real branches - its lines just connect points. You can calibrate a tree against geological time and the dates of fossils; you can make the branches thinner or thicker to depict their diversities; and you can artistically elongate some branches to suggest temporal, adaptive or ecological differences. Trees have few rules, and so they remain an eternal metaphor for biologists, perpetually dangling the tempting apple.

Archibald's book is interdisciplinary, authoritative, well-written and complete, with a deep historiographic appreciation of its many subjects. I wished for a concluding chapter that integrated all the delightful insights in the book, but that is a quibble. It is important in this context to note biologist Theodore Pietsch's complementary work Trees of Life (Johns Hopkins University Press, 2012). With its copious illustrations and economical but enlightening text, Pietsch's book is in some ways intermediate between Archibald's and Lima's.

Lima's Book of Trees is a catalogue that includes diagrams from biology, philosophy, technology, history and even comic books. They are not all genealogical trees; the book includes various kinds of diverging diagrams, some not even obviously treelike, such as rectangular concept maps. Some compare and even quantify differences in their variables, using their component lengths, thicknesses and directionalities.

As Archibald shows, Darwin used nearly every kind of treelike diagram in his notes and books. Lima's catalogue explains each of Darwin's beautifully reproduced images, but he does not dwell on analysis. For him, the strength of the representations is in their diversity, ability to convey information, and - let's face it - beauty. Clarity of expression is a wonderful thing: the graceful geometric skeletons of points and lines convey more conceptual dimensions than the page can literally express.

Kevin Padian is in the Department of Integrative Biology and the Museum of Paleontology at the University of California, Berkeley.

email:kpadian@berkeley.edu

\section{Books in brief}

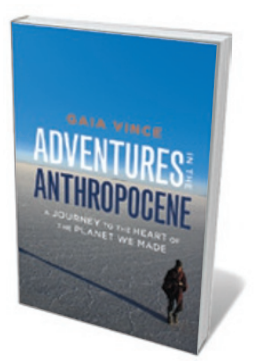

Adventures in the Anthropocene: A Journey to the Heart of the Planet We Made

Gaia Vince CHATTO \& WINDUS (2014)

When Nature's former news editor Gaia Vince set off on a two-year, six-continent trek, her aim was inspired: to explore empirically, amid biodiversity collapse and global climate change, how the planet and its ingenious humans are faring. Digging beneath the scree of statistics, received wisdom, "shock-doctrines and tired slogans", Vince has reached ground truths. Her broader discussions of the biological and Earth science are as cogent as her close reportage on innovators such as the Ladakhi 'glacier-maker' Chewang Norphel.

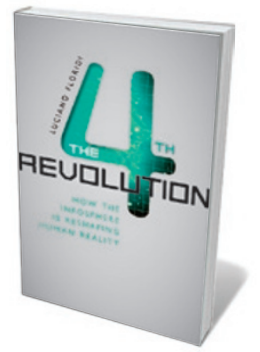

The Fourth Revolution: How the Infosphere is Reshaping Human Reality

Luciano Floridi OXFORD UNIVERSITY PRESS (2014)

Are we 'inforgs' living in 'onlife' - informational organisms inhabiting a blurry realm between real and virtual? Information ethicist Luciano Floridi thinks so, and his searing study of our digital dependency peels to the bone the implications for everything from identity to the environment. We look with new eyes at our transformation into generic online consumers ("Gogol's dead souls, but with wallets"), and our creation of an environment that is dumbed-down enough for smart technologies to excel. Non-alarmist and very, very smart.

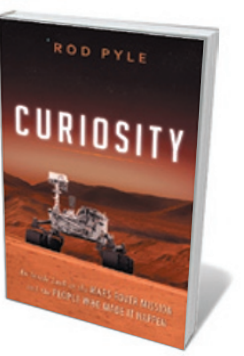

Curiosity: An Inside Look at the Mars Rover Mission and the People Who Made It Happen

Rod Pyle Prometheus Books (2014)

Ebullient science writer Rod Pyle follows his 2012 Destination Mars with more hot reportage of the red planet in this comprehensive study of NASA's Mars Science Laboratory mission and the US\$2.5-billion rover Curiosity. Pyle veers from the rover's battery of analytical instruments (one, notably, vaporizes rock) to its findings and operation, as well as the big personalities who make it happen. Gripping behind-the-scenes encounters abound, not least with the dedicated crew that controls the robotic arm remotely.

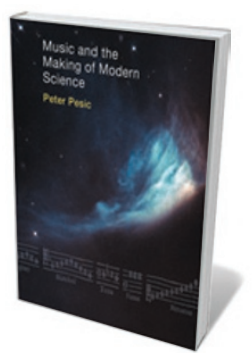

Music and the Making of Modern Science

Peter Pesic MIT PRESS (2014)

Mathematics, astronomy and music were closely allied in classical Greece. That chord has reverberated down the centuries, argues musician and science writer Peter Pesic. The fourteenth-century French philosopher Nicole Oresme, for instance, was an early proponent of heliocentrism who looked at celestial harmony in terms of music and geometry. Centuries later, physicist (and pianist) Max Planck's experiments with harmonium tuning may have inspired his thinking on black-body radiation, Pesic avers: there are analogies between tuning and the behaviour of electromagnetic waves.

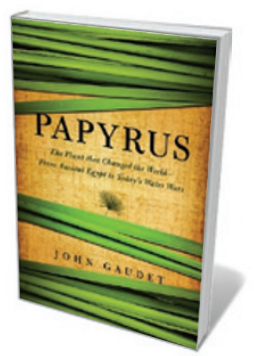

Papyrus: The Plant that Changed the World - From Ancient Egypt to Today's Water Wars

John Gaudet PEGASUS Books (2014)

In this swirling anthropological and environmental narrative, ecologist John Gaudet reminds us how papyrus was historically central to swathes of Africa. Gaudet takes us from the continent's ancient marsh-based cultures - in which the reed served as food, a construction material and the earliest form of paper - to today's imperilled wetlands. The reed beds should be reinstated, he argues: they are avian habitats and ideal heavy-metal filters. Barbara Kiser 